\title{
Chronic Stress Effects on Adrenal Cortex Cellular Proliferation in Pregnant Rats
}

\author{
Efectos del Estrés Crónico sobre la Proliferación Celular \\ en la Corteza Suprarrenal en Ratas Preñadas
}

*Aída Andrea Bozzo; "Carlos Alberto Soñez; ** Ignacio Monedero Cobeta; **** Rodolfo Avila; *Alicia Nélida Rolando; "María Cristina Romanini; "Mario Lazarte; ${ }^{* * * *}$ Héctor Fernando Gauna \& "María Teresa Mugnaini

BOZZO, A. A.; SOÑEZ, C. A.; COBETA, I. A.; AVILA, R.; ROLANDO, A. N.; ROMANINI, M. C.; LAZARTE, M.; GAUNA, H. F. \& MUGNAINI, M. T. Chronic stress effects on adrenal cortex cellular proliferation in pregnant rats. Int. J. Morphol., 29(4):11481157, 2011.

SUMMARY: Chronic stress by immobilization during pregnancy may cause alterations in mechanisms maintaining homeostasis in the adrenal gland. The objective of this study was to quantify cellular proliferation index in the adrenal cortex during pregnancy second half and assess the effects of chronic stress on it. Adrenal cortex proliferation index in stressed rats showed a significant decrease at 12 and 17 days of gestation, while at day 21 it did not show differences with the control treatments. Moreover, proliferation index of reticular zones in control and experimental rats, exhibited a significant reduction in comparison to glomerular and fascicular zones of adrenal cortex during the three gestation days studied. In conclusion, chronic stress by immobilization produces a decrease in cellular proliferation index at 12 and 17 gestation days, which may be related to changes in plasmatic concentrations of corticosterone and prolactin and, to the reduction of specific growth factors. Furthermore, the observed proliferation diminishment in reticular zone regarding the other cortical zones would be consistent with the migration theory of adrenal cells.

KEY WORDS: Chronic stress; Cellular proliferation; Adrenal cortex; Pregnancy.

\section{INTRODUCTION}

Appropriate physiological responses are necessary for the survival of every organism. Hypothalamus-pituitaryadrenal and sympathetic adreno-medullar axes are the systems mainly involved in maintaining homeostasis during the stress response, and the adrenal gland is an essential organ common to both systems (Ulrich-Lai et al., 2006). This latter gland is subject to dynamic structural changes including cellular proliferation and death. These two processes must be balanced to ensure integrity and functionality of the adrenal gland (Nussdorfer, 1986).

Several theories have been proposed to explain cellular replacement in the different zones of the adrenal cortex. On the one hand, migration theory describes cell proliferation in the external part of the cortex, their migration and differentiation from glomerular zone to fascicular zone and from there to reticular zone where they end up degenerating and dying (Idelman, 1978; Wolkersdörfer \& Bornstein, 1998). On the other hand, transformation theory suggests two transformation directions considering the replacement of zonal tissue by proliferative cells from the intermediate zone. This latter zone is placed between glomerular and fascicular zones and the cell migration occurs in two opposite directions: towards the medulla and towards the capsule. The transformation may occur locally either between glomerular and fascicular zones or between fascicular and reticular zones (Wolkersdörfer \& Bornstein). Last but not least, zonal theory sustains that both cellular proliferation and apoptosis occur independently in each cortical zone. Therefore, each zone might be locally regulated with no effects on the others functional behavior (Swann, 1940). All these hypothesis are based upon mammals histological observations under experi-

\footnotetext{
Biología Celular y Embriología, Dpto. de Anatomía Animal. Facultad de Agronomía y Veterinaria. Universidad Nacional de Río Cuarto, Argentina. Ruta 8 Km 601 Campus Universitario.

** Fisiología Animal, Dpto. de Biología. Facultad de Ciencias. Universidad Autónoma de Madrid. España.

*** II Cátedra de Histología y Embriología. Facultad de Ciencias Médicas, Universidad Nacional de Córdoba, Argentina.

***** Fisiología Animal, Dpto. de Biología Molecular. Facultad de Ciencias Exactas, Físico- Químicas y Naturales. Universidad Nacional de Río Cuarto, Argentina.
} 
mental conditions such as pharmacologic manipulation, castration or unilateral adrenalectomy. Such experimental conditions are needed to induce an increase of cellular proliferation in adrenal cortex, since in normal conditions cellular replacement in adult mammals adrenal cortex is quite slow. However, despite the numerous studies on this topic, there is still limited knowledge of adrenocortical cellular kinetics (Kataoka et al., 1996).

When chronic intermittent stress of enough intensity such as immobilization is applied, an increase in adrenal gland size is observed. This size increase is much more evident in relative weight due to animal loss of body mass (Pastorino et al., 1998). This may be related to a maximum increase in corticosterone (CORT) levels as a consequence of the trophic effect of adrenocorticotrophine (ACTH) hormone liberation. It is likely, although, that some other factors may be contributing to the observed response. The adrenal gland size increase is accompanied by an increase of in vivo and in vitro adrenal cortex response to ACTH (Armario \& Jolin, 1989).

In clinical studies in humans and animals it was proven that circulating levels of ACTH are positively correlated to adrenal size and that the ACTH chronic hypersecretion induces diffuse bilateral hyperplasia of the adrenal gland (Kobayashi et al., 2006).

ACTH is known to have a proliferative effect on adrenal gland. It was demonstrated that its chronic liberation induces extracellular signal regulated kinases (ERKs) activation and that these latter play an crucial role in cellular proliferation induction (Ferreira et al., 2007).

Under chronic stress conditions, it has not been possible to determine neither if the increased weight in adrenal gland is produced by hypertrophy or hyperplasia, if cellular growth occurs everywhere in the cortex or if it is localized in only some zones (Ulrich-Lai et al.).

The aim of this work was to determine cellular proliferation index at the adrenal cortex of pregnant rats using two immunocytochemical techniques: proliferating cell nuclear antigen and bromodeoxiuridine at 12, 17 and 21 days of gestation, and to assess whether chronic stress is able to change or not, the adrenal cellular proliferation.

\section{MATERIAL Y METHOD}

Animals used and laboratory conditions. Wistar female rats of three to four months of age were used for the experiment. They weighted 200 to $300 \mathrm{~g}$ at the beginning of the experiment. They were maintained under controlled laboratory conditions with food and water ad libitum, controlled photoperiod (12/12 h. light/darkness from 7.30 $\mathrm{AM}$ to $7.30 \mathrm{PM}$ ) and temperature $20 \pm 2{ }^{\circ} \mathrm{C}$ (Laboratory installations met the requirements of 6344/96 disposition of the Administración Nacional de Medicamentos, Alimentos y Tecnología Médica, Argentina). The Conclusions and Recommendation on the Reduction, Refinement and Replacement of Laboratory Animals Procedure of Declaration of Bologna were followed for animal experimentation. All experiments were conducted according to the principles and procedures of the NIH Guide for the Care and Use of Laboratory Animals (NIH publication $\mathrm{n}^{\circ} 85-23$, reviewed 1985; http://www.nih.gov/ sigs/bioethics).

Rats were cycled with colpocytograms and they were mated during the proestrous with a same strain male. For the purpose of programmed sacrifice, the pregnant day zero was stated when spermatozoid presence in vaginal fluid was verified. Pregnant rats were split into two groups that remained physically separated: control (CR) and experimental (ER) rats.

Experimental Treatment. From the fourth gestation day ER group was subject to 45 minute sessions of immobilization (IMO) stress on boards, every other day, until the day before sacrifice (Michajlovskij et al., 1988). CR and ER were sacrificed by decapitation at 12, 17 and 21 days of gestation. For Proliferating Cell Nuclear Antigen (PCNA) determination, five (5) rats per gestation age group were used as CR and ER. For Bromodeoxiuridine (BrDU) determination, on the other hand, four groups were formed: control rats injected with physiological solution (C-F), control rats injected with $\mathrm{BrDU}(\mathrm{C}-\mathrm{BrDU})$, stressed rats injected with physiological solution (E-F) and stressed rats injected with BrDU (E-BrDU). There was a minimum of 5 individuals per group. In pertinent groups, an intraperitoneal injection of 5-bromine-2'deoxiuridine (100 mg/kg; Sigma) was applied 24 hours before sacrifice.

The adrenal glands of each pregnant rat from CR and ER groups were extracted. They were fixed in buffered formaldehyde and processed according to the conventional histological technique. Alternate sections of $5 \mathrm{~mm}$ were obtained from adrenal cortex by means of a Reichert-Young 2065 microtome and they were mounted in each slide previously treated with Vectabond adhesive (Vector Laboratories, Inc, Burlingame, USA). Glomerular, fascicular and reticular zones of the adrenal cortex were identified according to their classical histological characteristics. 
Immunocytochemical Techniques. PCNA detection. An indirect immunocytochemical method (Vectastain ABC elite kit- 6200, Vector) was used in 360 sections; 180 from CR and 180 from ER. Sections were deparaffinized and hydrated in saline phosphate buffer (PBS) $\mathrm{pH}$ 7.4. Then, endogen peroxidases were blocked with a $20 \%$ hydrogen peroxide solution for 30 minutes. Unspecific antibodies were neutralized with blotto ( $5 \mathrm{gr}$ of skim milk powder solved in $100 \mathrm{ml}$ of PBS $+1 \mathrm{ml}$ of triton). Mice monoclonal antibody (Enzo Diagnostic) diluted 1:50 in PBS (pH 7.4) for 24 hours at $4{ }^{\circ} \mathrm{C}$ was used as primary anti-PCNA antibody. Sections were then incubated with second and third antibodies (Vectastain ABC elite kit- 6200, Vector) for 60 minutes at room temperature. They were revealed with a diaminobenzidine 3-3' tetrahydrochloride (DAB) (Vector) solution for 3 minutes and nuclear contrast staining was performed with $1 \%$ methyl green in sodium acetate. Finally, sections were dehydrated, cleared and mounted with Entellan (Merck).

BrDU detection. A direct immunocytochemical method (Dako, LSAB + System- HRP) was used in 360 sections; 180 from CR and 180 from ER. Sections were deparaffinized and hydrated in PBS, pH 7.4. For endogen peroxidases blocking they were put in a $30 \%$ hydrogen peroxide solution for 30 minutes. DNA was denaturalized with $2 \mathrm{~N}$ hydrochloric acid at $37{ }^{\circ} \mathrm{C}$ for 30 minutes. Unspecific antibodies were blocked with horse serum (Vector) for 30 minutes. Mice monoclonal antibody (NCL-BrDU. Novocastra) diluted 1:200 in PBS pH 7.4 for 24 hours at 4 ${ }^{\circ} \mathrm{C}$ was used as primary anti-BrDU antibody. Second and third antibodies (Dako, LSAB + System- HRP) were incubated for 30 minutes at room temperature. Antigenantibody complex was then revealed with $\mathrm{DAB}$ (from the kit used) for 5 minutes. Finally, after nuclear contrast staining with $1 \%$ green methyl in sodium acetate, sections were dehydrated, cleared and mounted with Entellan (Merck).

For both immunocytochemical techniques, adrenal cortex tissue without the pertinent primary antibody was used as negative control and small intestine sections as positive control.

Images Stereological Analysis. From each adrenal cortex histological section 10 to 12 images from glomerular, fascicular and reticular zones were scanned to build a raw image data base for CR and ER. A Zeiss Axiophot microscope with a built in AxioVision Zeiss digital camera and associated softwares (video-Printer Sony 3000 and Scion stereological image analysis software) was used. For each image, the number of positively marked cells either with anti-PCNA antibody or with anti-BrDU antibody (in proliferation process) was quantified. Number of unmarked cells (contrasted with green methyl) was also quantified for each image. Cellular proliferation index (PI) was estimated as the ratio between proliferating and normal cells multiplied by 100 . Data obtained were transferred to a data base in Excell software for further statistical analysis.

Statistical analysis. An exploratory and descriptive analysis was performed to study PI behavior. One and three ways ANOVAs were applied. A logarithmic linear model with Poisson distribution and including, group and time effects as well as their interactions was also applied. Differences were considered significant at $p<0.05$. All statistical analyses were performed using InfoStat y SAS 9.1 softwares.

\section{RESULTS}

Considering that in materials and methods section the conformation of two groups was proposed (stress and control without BrDU injection), a test was performed with several histological slides from each group with the application of anti-BrDU antibody in order to determine if the injection caused any alteration by stress. Results for this test were negative for both groups.

Qualitative analysis of adrenal cortex cellular proliferation. PCNA marked nuclei were distributed in the three zones of adrenal cortex, but they were more abundant in CR than in ER at 12 and 17 days of gestation. BrDU marked nuclei, on the other hand, were more frequently observed in glomerular and fascicular zones and scarcer in the reticular zone for the three gestation days studied. Similar to PCNA treatment, BrDU marked nuclei were less frequent in ER (Figs. 1, 2, 3 and 4).

\section{Quantitative analysis of adrenal cortex cellular proliferation.}

A. Total PI in adrenal cortex of pregnant rats.

PCNA and BrDU. A significant $(\mathrm{p}<0.001)$ interaction between treatment and gestation day was observed for days 12 and 17, while no interaction was recorded for day 21 (Figs. 5 and 6).

B. PI in the different adrenal cortex zones of pregnant rats.

PCNA: Both in CR and ER, PI showed a significant $(p<0.001)$ decrease in reticular zone for the three gestation days studied compared to glomerular and fascicular adrenal cortex zones (Figs. 7 and 8). 


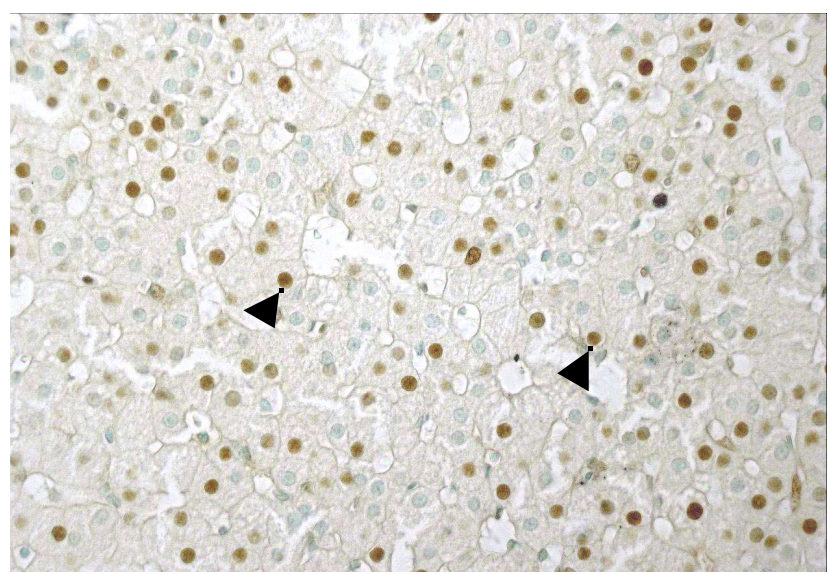

Fig. 1. Optic micrograph of the adrenal cortex of a control rat at 17 days of pregnancy treated with PCNA and stained using green methyl (400x).

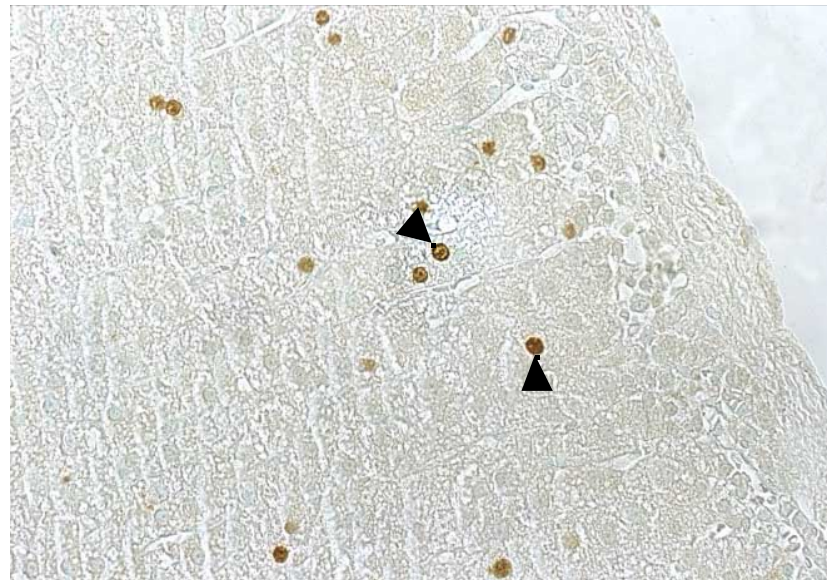

Fig. 3. Optic micrograph of the adrenal cortex of a control rat at 12 days of pregnancy treated with BrDU and stained using green methyl (400x).

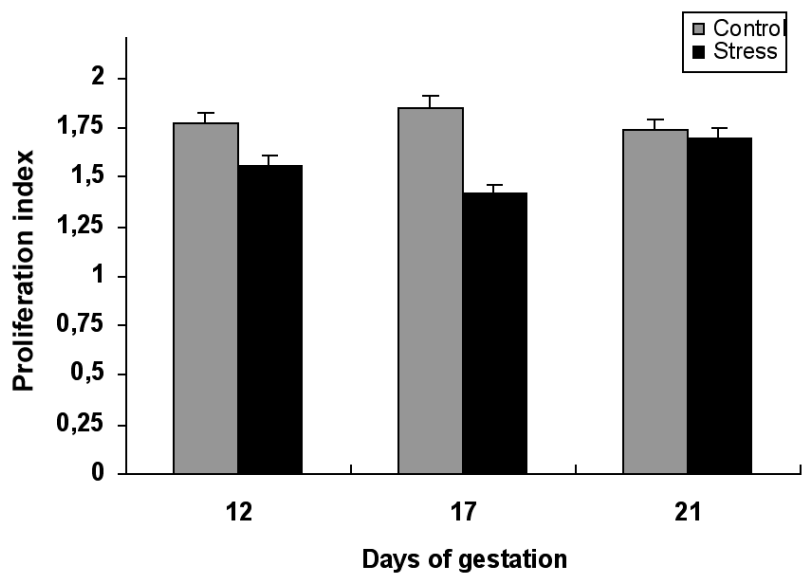

Fig. 5. Proliferation index of adrenal cortex with PCNA in pregnant rats.

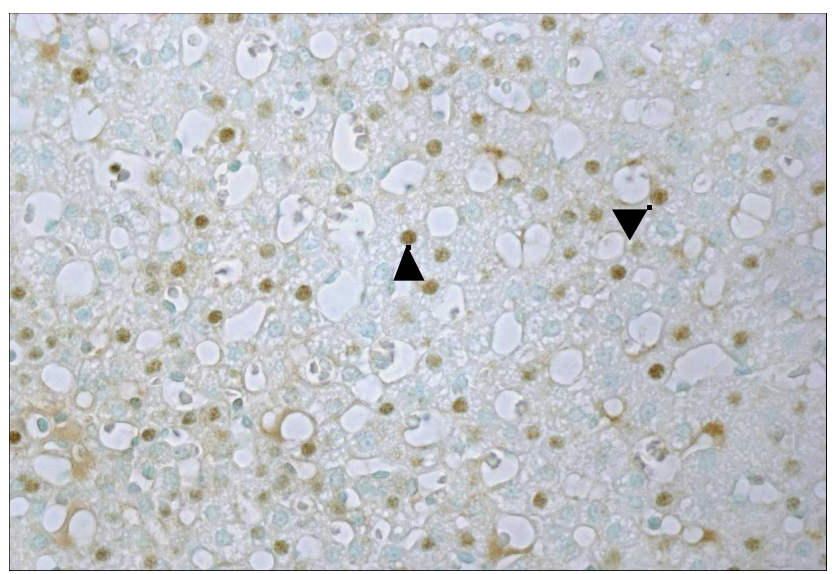

Fig. 2. Optic micrograph of the adrenal cortex of a stressed rat at 17 days of pregnancy treated with PCNA and stained using green methyl (400x).

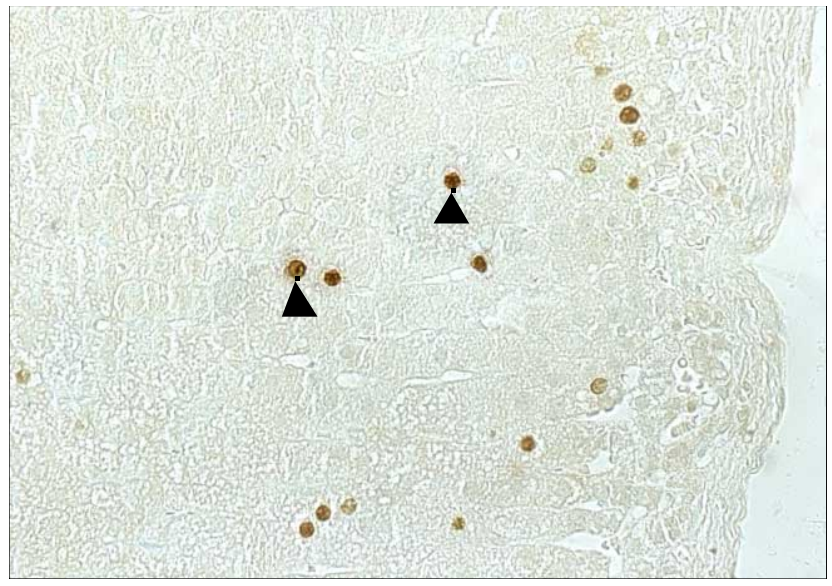

Fig. 4. Optic micrograph of the adrenal cortex of a stressed rat at 12 days of pregnancy treated with $\mathrm{BrDU}$ and stained using green methyl (400x).

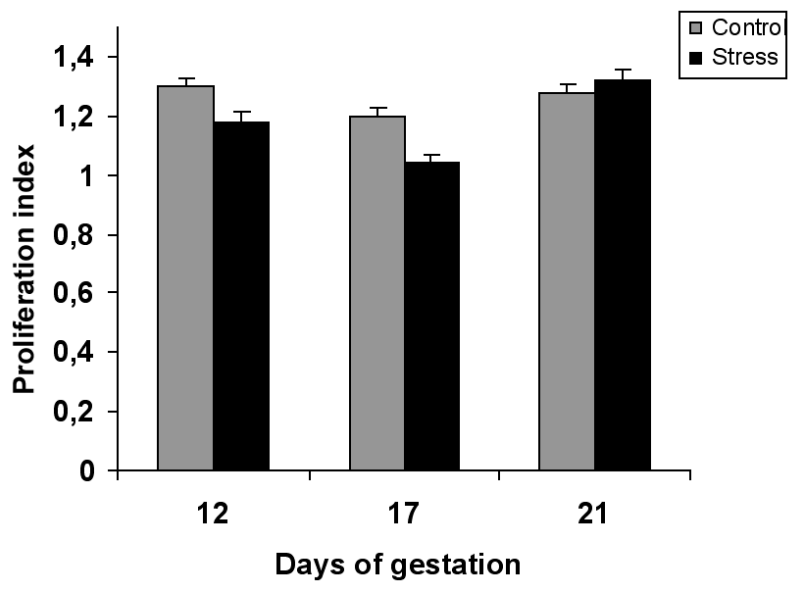

Fig. 6. Proliferation index of adrenal cortex with BrDU in pregnant rats. 


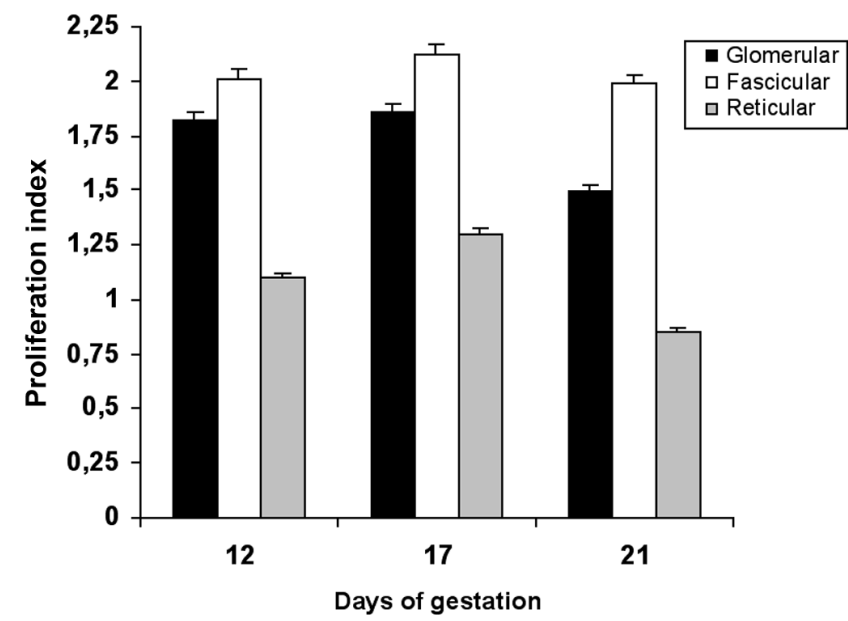

Fig. 7. Proliferation index with PCNA of adrenal cortex different zones in pregnant control rats.

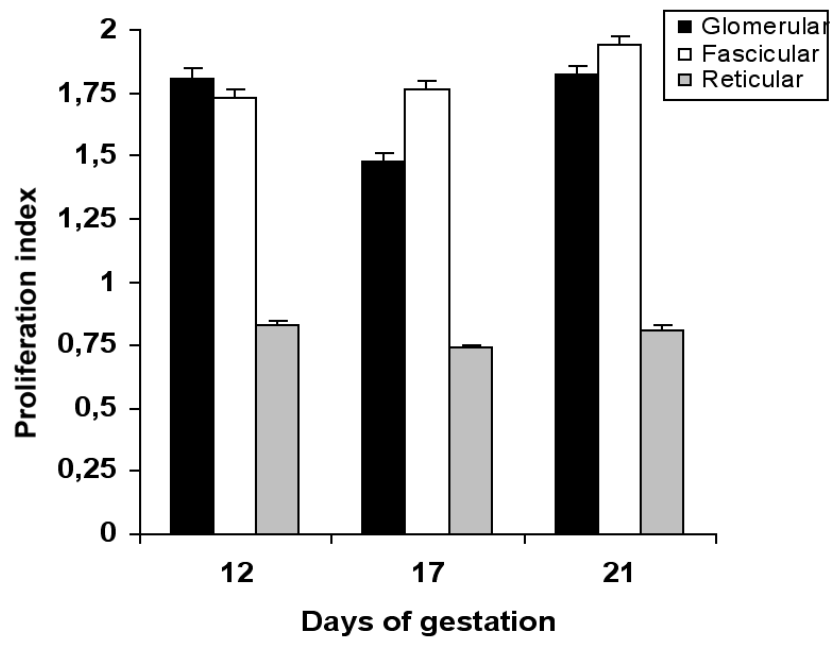

Fig. 8. Proliferation index with PCNA of adrenal cortex different zones in pregnant stressed rats.

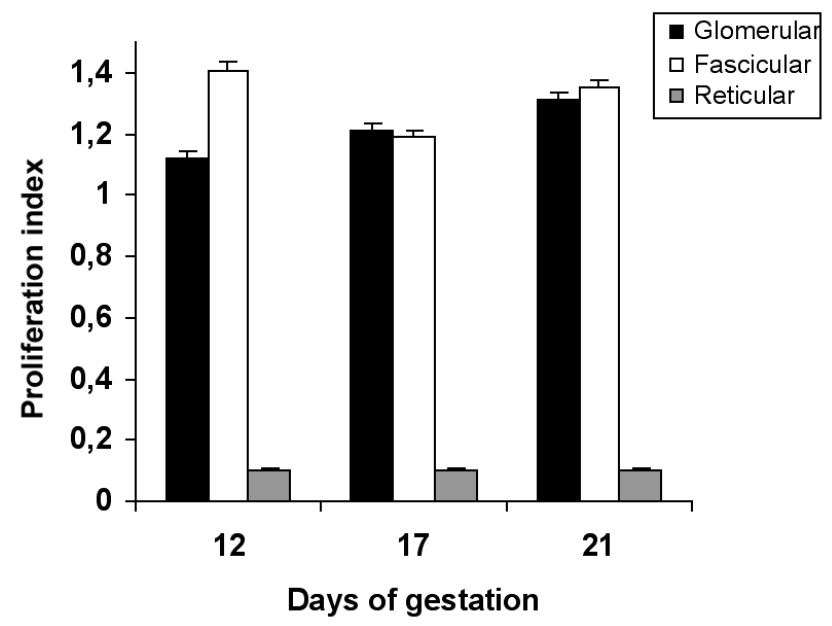

Fig. 9. Proliferation index with BrDU of adrenal cortex different zones in pregnant control rats.

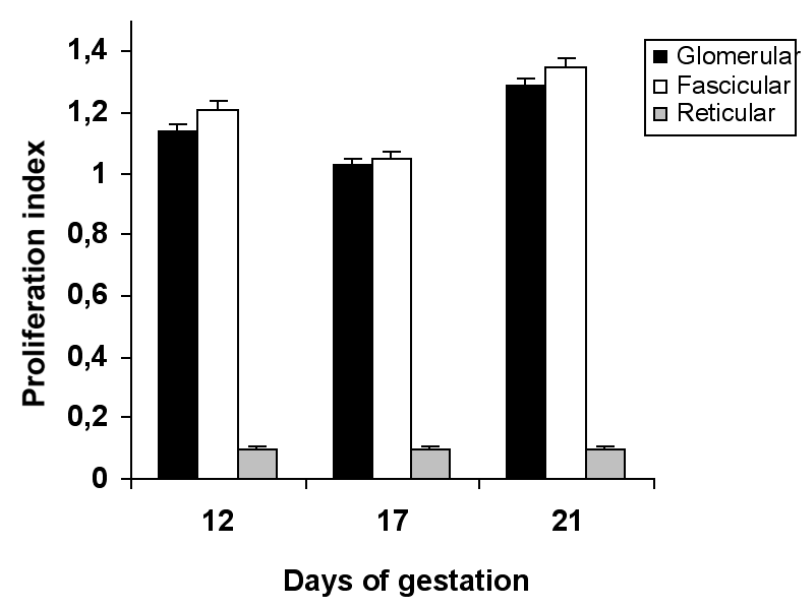

Fig. 10. Proliferation index with BrDU of adrenal cortex different zones in pregnant stressed rats.

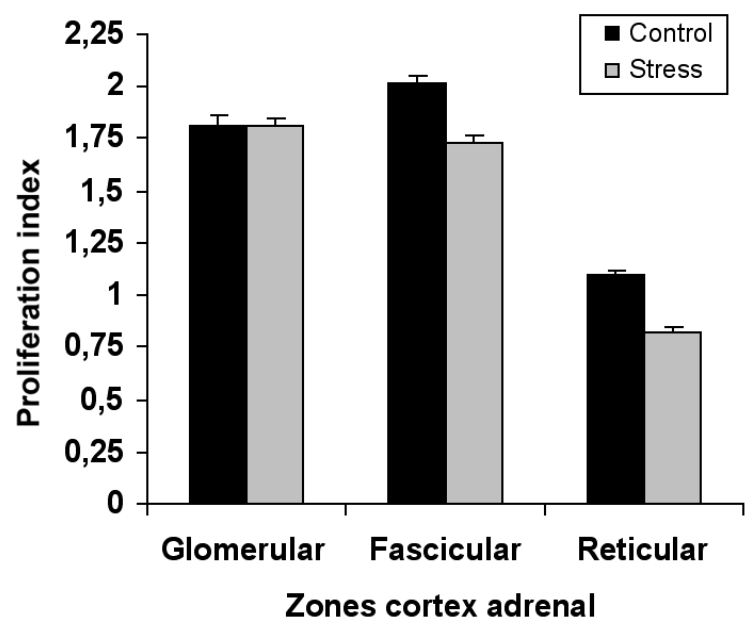

Fig. 11. Proliferation index with PCNA for adrenal cortex of pregnant rats at 12 days of gestation.

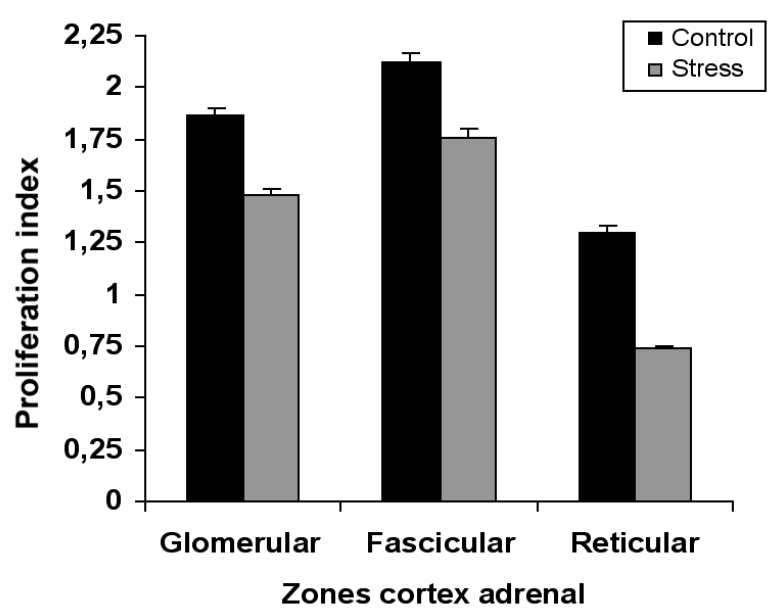

Fig. 12. Proliferation index with PCNA for adrenal cortex of pregnant rats at 17 days of gestation. 
BrDU: PI of CR at gestation day 12 yielded significant differences among the three adrenal cortex zones, while PI at gestation days 17 and 21 was significantly $(\mathrm{p}<0.001)$ lower in reticular zone than in glomerular and fascicular zones, which did not show differences from each other (Fig. 9). The reticular zone PI in ER showed a significant $(\mathrm{p}<0.001)$ decrease regarding glomerular and fascicular zones for the three gestation days studied (Fig. 10).

C. Zone-Treatment interaction effect on PI at 12, 17 and 21 days of gestation.

PCNA: Gestation day 12: fascicular and reticular zones showed interaction with treatment and PI. ER PI was significantly lower than CR PI (Fig. 11).

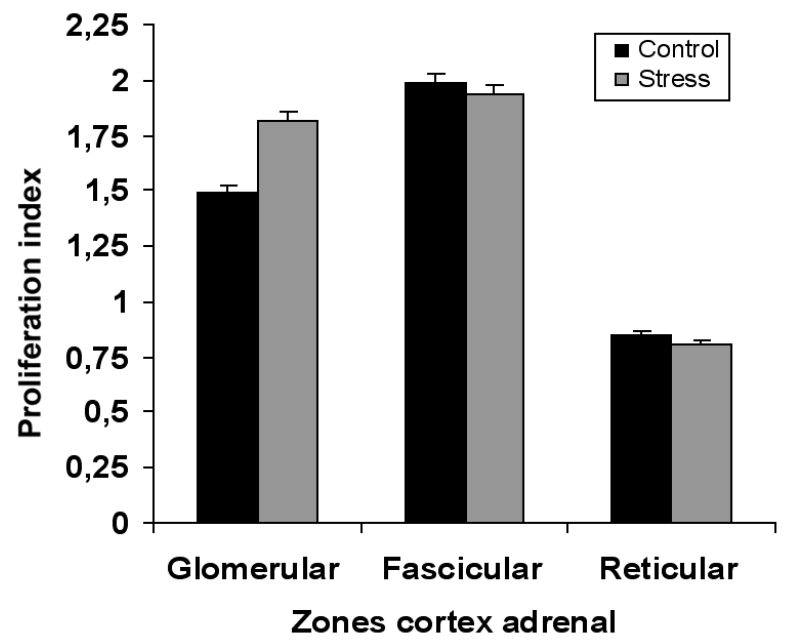

Fig. 13. Proliferation index with PCNA for adrenal cortex of pregnant rats at 21 days of gestation.

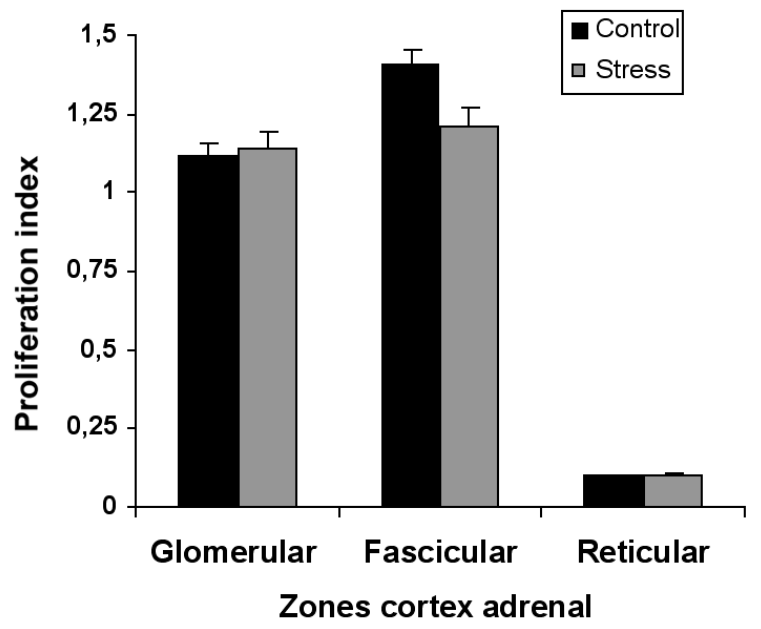

Fig. 14. Proliferation index with BrDU for adrenal cortex of pregnant rats at 12 days of gestation.
Gestation day 17: all adrenal cortex zones showed interaction with treatment and PI. As in gestation day 12, ER PI was significantly lower than CR PI (Fig. 12).

Gestation day 21: no interaction was observed between adrenal cortex zones and treatment or PI (Fig. 13).

BrDU: Gestation day 12: fascicular zone showed interaction with treatment and PI. ER PI was significantly lower than CR PI (Fig. 14).

Gestation day 17: glomerular and fascicular zones presented interaction with treatment and PI. Again, ER PI was lower than that of CR (Fig 15).

Gestation day 21: there was no evident interaction of adrenal cortex zones neither with treatment nor with PI (Fig. 16).

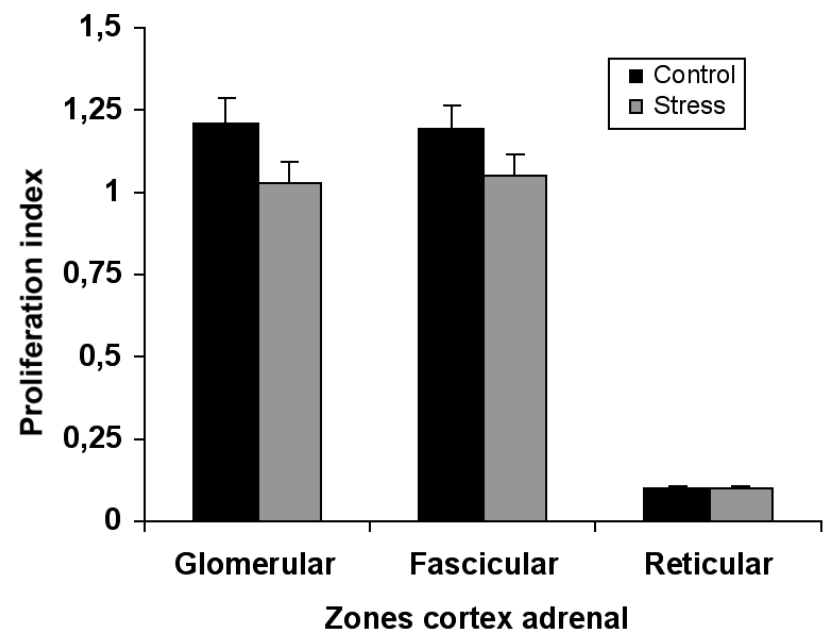

Fig. 15. Proliferation index with BrDU for adrenal cortex of pregnant rats at 17 days of gestation.

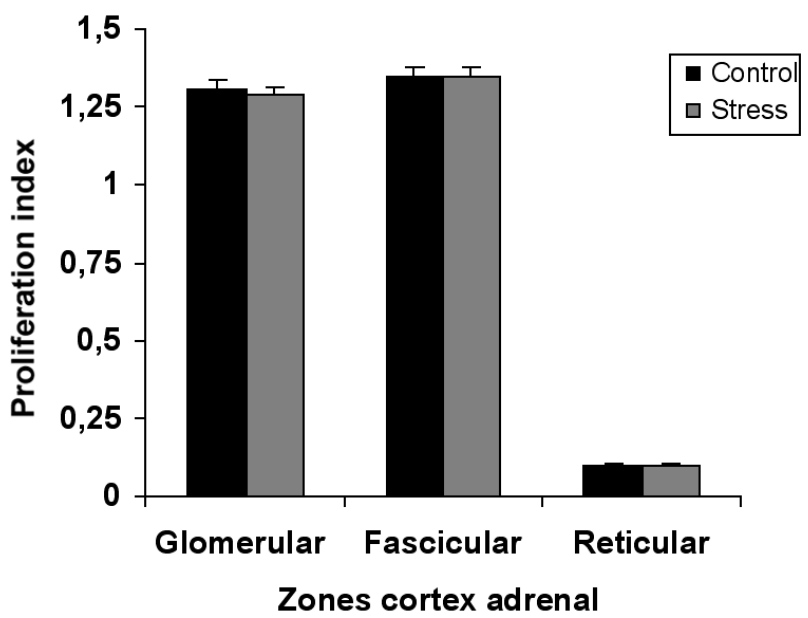

Fig. 16. Proliferation index with BrDU for adrenal cortex of pregnant rats at 21 days of gestation. 


\section{DISCUSSION}

Results obtained in this study demonstrate that chronic stress produced by repeated intermittent immobilization applied during the second half of gestation period causes a decrease in PI at days 12 and 17, while it has no apparent effect at day 21. Statistical results obtained with PCNA and BrDU techniques are consistent, although PI estimated with PCNA is higher than the PI obtained by BrDU. This observed difference between techniques may be due to different marked cell populations. The fraction of cell nuclei marked with PCNA is the cell population in late G1, early S phase and DNA synthesis period, while BrDU is only incorporated in cells during DNA synthesis and repairing, offering more precise estimations (Connolly \& Bogdanffy, 1993; Baccaro et al., 2007).

The decrease in ER PI might be related to plasmatic levels of CORT 24 hours after immobilization stress exposure at gestation days $12,15,17,19$ and 21, given that stressed pregnant rats had higher plasmatic CORT levels than control rats of the corresponding gestation day (Romanini et al., 1999).

These results could be explained by the effect of glucocorticoids (GC) on insulin-like growth factors, mainly type 1 (IGF-1). These growth factors are able to activate or repress specific genes promoting cell survival, proliferation and death when they interact with little hydrophobic molecules such as GC (Czech, 1989).

It has been demonstrated that IGF-1 levels diminish in response to nutrient restriction and/or hypoinsulinemia. Regarding hypoinsulinemia and stress, it is well known that metabolic activation caused by sympathetic adreno-medullar and pituitary-adrenal systems is opposite to insulin effects. That is why in stress situations insulin secretions would be inhibited most likely by a a-adrenergic direct effect on pancreas b cells (Porte \& Robertson, 1973).

Furthermore, it has been described that GC mask IGF receptors, causing a decrease in cell growth (Collins et al., 1994) that might be reflected in the observed PI reduction at the adrenal cortex. This shows the harmful effect produced by stress through maternal metabolic and hormonal changes that would influence IGF synthesis and/or expression via maternal GC and/or fetal GC liberated in response to stress. Plasmatic levels of CORT constitute a clear evidence of chronic stress: rat approaches delivery time and immobilization represents an intense stressogenic stimulus until the end of gestation, precluding adaptation or habituation.
In stress situations, the hypothalamus-pituitaryadrenal axis is activated and a rapid liberation of ACTH occurs. ACTH stimulates GC synthesis in the fascicular zone of the adrenal cortex. When the stimulus persists, even when it is highly intense, pituitary-adrenal hormones gradually return to normal levels. However, only ACTH displays this pattern, but not GC which remains in high levels (Martí \& Armario, 1998).

Progressive reduction of ACTH is partially due to the negative feedback of GC and to the decrease in pituitary ACTH content. Pathways and signals regulating cell number and size in response to ACTH stimulation are very complex and they are the focus of multiple current research. Several authors have suggested that ACTH is a proliferative hormone that acts as a primary homeostasis regulator in adult adrenal gland, after finding a correlation between ACTH circulating levels and adrenal cortex size. On the contrary, "in vitro" studies have indicated that ACTH is a weakly mitogenic hormone in adrenocortical Y-1 tumor cells and antimitogenic hormone in cell lines and primary adrenocortical cultures from rats, mice and humans (Mattos \& Lotfi, 2005). These observations suggest that "in vivo", ACTH is an indirect mitogenic hormone, likely mediated by other paracrine factors such as IGF and fibroblastic growth factor (FGF), which have a proliferative effect on adrenocortical cells (Vinson \& Ho, 1998).

ACTH blocks progression of adrenocortical cells in G1 phase and inhibits DNA synthesis in S phase, even in presence of growth factors. After this inhibiting effect, ACTH induces expression of genes associated with cell cycle progression such as c-fos and c-jun. However, it is not clear yet whether the latter is a direct effect of ACTH or if it is a consequence of the hypertrophy and/or activation of some growth factor (Viard et al., 1994).

It was also demonstrated that high ACTH plasmatic levels cause hypertrophy in adrenocortical cells (Vinson, 2003). This was observed in rats and mice treated with ACTH and, in genetic models with high concentrations of $\mathrm{ACTH}$ like knockout mice for $\mathrm{GC}$ receptors. In contrast, low plasmatic levels of ACTH in knockout mice for CRH and POMC or, in hypophysectomized rats, cause adrenocortical tissue regression with persistence of glomerular zone cells and disappearance of fascicular and reticular zone cells by apoptosis (Bland et al., 2003).

ACTH exhibits this dual effect since in short inputs before the onset point in G1, it induces cell cycle progression 
by promoting transition from $\mathrm{G} 1$ to $\mathrm{S}$ phase increasing cellular proliferation. On the contrary, a prolonged exposure to ACTH during $\mathrm{G} 1$ arrests cell growth by blocking transition to $\mathrm{S}$ phase (Bland et al.)

Another important factor in adrenocortical growth is FGF, which under ACTH stimulation, favors cells progression from $\mathrm{G} 1$ to $\mathrm{S}$ phase, since it induces c-fos and c-jun expression. Therefore, ACTH and FGF employ a common pathway of intracellular signals to promote cell cycle progression (Bland et al.). In our experimental model, the decrease in ACTH levels and the sustained increase in GC concentrations could be responsible for PI diminishment in adrenal cortex at 12 and 17 days of gestation. It was also proven, that prolonged high plasmatic concentrations of CORT as it occurs at gestation day 21, mask GC (Mizoguchi et al., 2001) receptors and that would be the reason why there were no evident PI changes in ER at this point.

CR and ER reticular PI showed a significant decrease regarding glomerular and fascicular zones of adrenal cortex at the three gestation days studied. These results would be related to those obtained for apoptotic index (AI) both in $\mathrm{CR}$ and ER, since it was demonstrated that the latter shows high values in reticular zone, followed by fascicular zone and lastly by glomerular zone, where the lowest values are observed (unpublished data). These findings would be in agreement with migration theory of adrenal cells.

It was proven that parental cells proliferation is limited to the outer part of the cortex and that then adrenal cells move in centripetal direction towards the cortex inner part limiting the medulla. This process lasts approximately 100 days in rats. Approximately a half of cells dies during migration and a large number of them are eliminated by apoptosis in the reticular zone (Feige et al., 1998).

PI at gestation day 12 in fascicular and reticular zones with PCNA and in fascicular zone with BrDU showed a significant reduction in ER compared to $\mathrm{CR}$, while at gestation day 17 the three adrenocortical zones with PCNA and the glomerular and fascicular zones with BrDU showed a significant decrease in ER. Baccaro et al. demonstrated that when administrating pharmacological doses of ACTH in vivo, fascicular and reticular zones showed an increase in DNA synthesis and in the expression of early response genes for Jun and Fos proteins related to cycle progression. However, this effect was inhibited when animals were previously treated with dexametasone (Baccaro et al.). In chronic stress conditions, high CORT levels may act in the adrenal gland causing a decrease in cellular proliferation by blocking the expression of genes involved in cell cycle progression.
Immobilization stress produces an increase in $\mathrm{Y}$ neuropeptide (NPY) concentrations at adrenal cortex and medulla. Most studies about adrenal NPY regulation do not differentiate cortical from medullar peptide. Others assume that the origin is only medullar. Some authors however, have found immunoreactive fibers for NPY at the adrenal cortex of rats with higher proportions in fascicular and reticular zones (Renshaw \& Hinson, 2001).

In vivo experiments with intraperitoneal doses of NPY administrated for a prolonged time or by continuous perfusion have obtained a proliferation reduction at glomerular and fascicular zones accompanied by glomerular hypertrophy (Renshaw \& Hinson). It was demonstrated that NPY perfusion into the adrenal gland diminishes local blood flow in a dose-dependent way, probably through arteriolar vasoconstriction (Renshaw \& Hinson). This diminishment of blood flow may cause a lower availability of growth factors acting at the adrenal cortex and producing a decrease in adrenocortical cellular proliferation under stress conditions.

Although several stress factors increase adrenal NPY, it still has not been proven that this may influence NPY plasmatic concentrations, so this peptide may be considered a paracrine agent of adrenal gland instead of a hormonal product (Bernet et al., 1998).

Spexine, a polipeptide involved in stress response in adrenocortical rat cortex, was recently identified. Although it is expressed in the three zones of adrenal cortex, it has been found in higher concentrations in both fascicular and reticular zones. Moreover, it has been demonstrated that Spexine has a strong inhibiting effect upon proliferative activity at the adrenal cortex under stress conditions (Rucinski et al., 2010).

In previous studies it was demonstrated that adrenal glands total weight in ER showed a similar curve to that of $\mathrm{CR}$, but there was a significant weight increase in ER at gestation day 17 (Soñez, 2001). However, if the mechanism responsible for that weight increase was hypertrophy, hyperplasia or decreased cellular apoptosis remained unknown.

It could be inferred that $\mathrm{AI}$ is related to adrenal glands weight given that at gestation day 17 a lower AI was observed in fascicular and reticular zones in ER (unpublished data).

Regarding cellular proliferation, PI was higher in glomerular and fascicular zones and lower in the reticular zone. Chronic stress caused a reduction in adrenal cortex proliferation and apoptosis processes, therefore it could be 
inferred that the gland increased weight would be due to cellular hypertrophy.

Besides, prolactin plasmatic levels significantly increased in ER at gestation day 17 (Soñez et al., 1996). This might be a factor inhibiting apoptosis and inducing adrenal hypertrophy, since hyperprolactinemia causes increased adrenal weight as a consequence of cellular hypertrophy (Silva et al., 2004).
In conclusion, chronic stress by immobilization produces a decrease in cellular proliferation index at gestation days 12 and 17, which may be related to changes in plasmatic concentrations of corticosterone and prolactin and, to the reduction of specific grow factors. Furthermore, the observed proliferation diminishment in reticular zone regarding the other cortical zones would be consistent with the migration theory of adrenal cells.

BOZZO, A. A.; SOÑEZ, C. A.; COBETA, I. A.; AVILA, R.; ROLANDO, A. N.; ROMANINI, M. C.; LAZARTE, M.; GAUNA, H. F. \& MUGNAINI, M. T. Efectos del estrés crónico sobre la proliferación celular en la corteza suprarrenal en ratas preñadas. Int. J. Morphol., 29(4):1148-1157, 2011.

RESUMEN: El estrés crónico por inmovilización durante la gestación puede provocar alteraciones de los mecanismos que mantienen la homeostasis en la glándula adrenal. El objetivo de este trabajo fue cuantificar el índice de proliferación en la corteza adrenal durante la segunda mitad de la gestación y comprobar los efectos que produce el estrés crónico sobre el mismo. El índice de proliferación en la corteza adrenal de ratas estresadas presentó una disminución significativa a los 12 y 17 días de gestación, mientras que en el día 21 no presentó modificaciones con respecto a sus controles. Por otro lado, el índice de proliferación de la zona reticular en ratas controles y experimentales, presentó una disminución significativa con respecto a las zonas glomerular y fascicular de la corteza adrenal en los tres días de la gestación estudiados. Se puede concluir que el estrés crónico por inmovilización produce disminución del índice de proliferación celular a los 12 y 17 días de la gestación que podría estar en relación con las variaciones de las concentraciones plasmáticas de corticosterona, prolactina, y con la disminución de factores de crecimiento específicos. Asimismo, la disminución de la proliferación en la zona reticular en relación con las otras zonas corticales estaría en concordancia con la teoría de la migración celular adrenal.

PALABRAS CLAVE: Estrés crónico; Proliferación celular; Corteza adrenal; Gestación.

\section{REFERENCIAS BIBLIOGRÁFICAS}

Armario, A. \& Jolin, T. Influence of intensity and duration of exposure to various stressors on serum TSH and GH levels in adult male rats. Life Sci., 44(3):215-21, 1989.

Baccaro, R. B.; Mendonça, P. O.; Torres, T. E. \& Lotfi, C. F. Immunohistochemical Jun/Fos protein localization and DNA synthesis in rat adrenal cortex after treatment with ACTH or FGF2. Cell Tissue Res., 328(1):7-18, 2007.

Bernet, F.; Dedieu, J. F.; Laborie, C.; Montel, V. \& Dupouy, J. P. Circulating neuropeptide Y (NPY) and catecholamines in rat under resting and stress conditions. Arguments for extra-adrenal origin of NPY, adrenal and extra-adrenal sources of catecholamines. Neurosci. Lett., 250(1):45-8, 1998.

Bland, M. L.; Desclozeaux, M. \& Ingraham, H. A. Tissue growth and remodeling of the embryonic and adult adrenal gland. Ann. N. Y. Acad. Sci., 995:59-72, 2003.

Czech, M. P. Signal transmission by the insulin-like growth factors. Cell, 59(2):235-8, 1989.

Collins, M. K.; Perkins, G. R.; Rodriguez-Tarduchy, G.; Nieto, M. A. \& López-Rivas, A. Growth factors as survival factors: regulation of apoptosis. Bioessays, 16(2):133-8, 1994.
Connolly, K. M. \& Bogdanffy, M. S. Evaluation of proliferating cell nuclear antigen (PCNA) as an endogenous marker of cell proliferation in rat liver: a dual-stain comparison with 5-bromo-2'-deoxyuridine. J. Histochem. Cytochem., 41(1):1$6,1993$.

Feige, J. J.; Keramidas, M. \& Chambaz, E. M. Hormonally regulated components of the adrenocortical cell environment and the control of adrenal cortex homeostasis. Horm. Metab. Res., 30(6-7):421-5, 1998.

Ferreira, J. G.; Cruz, C. D.; Neves, D. \& Pignatelli, D. Increased extracellular signal regulated kinases phosphorylation in the adrenal gland in response to chronic ACTH treatment. $J$. Endocrinol., 192(3):647-58, 2007.

Idelman, S. General comparative and clinical endocrinology of adrenal cortex. In: Adrenal cortex. Jones, I. C. (Ed.). London, Academic Press, 1978. pp.1-119

Kataoka, Y.; Ikehara, Y. \& Hattori, T. Cell proliferation and renewal of mouse adrenal cortex. J. Anat., 188(Pt 2):375$81,1996$.

Kobayashi, H.; Kambe, F.; Imai, T.; Hibi, Y.; Kikumori, T.; Ohmori, S.; Nakao, A. \& Seo, H. Differential expression of 
cyclin-dependent kinase inhibitors, p27Kip1 and p57Kip2, by corticotropin in rat adrenal cortex. J. Endocrinol., 189(3):671-9, 2006.

Martí, O. \& Armario, A. Anterior pituitary response to stress: time-related changes and adaptation. Int. J. Dev. Neurosci., 16(3-4):241-60, 1998.

Mattos, G. E. \& Lotfi, C. F. Differences between the growth regulatory pathways in primary rat adrenal cells and mouse tumor cell line. Mol. Cell. Endocrinol., 245(1-2):31-42, 2005.

Michajlovskij, N.; Lichardus, B.; Kvetnansk, R. \& Ponec, J. Effect of acute and repeated immobilization stress on food and water intake, urine output and vasopressin changes in rats. Endocrinol. Exp., 22(3):143-57, 1988.

Mizoguchi, K.; Yuzurihara, M.; Ishige, A.; Sasaki, H.; Chui, D. H. \& Tabira, T. Chronic stress differentially regulates glucocorticoid negative feedback response in rats. Psychoneuroendocrinology, 26(5):443-59, 2001.

Nussdorfer, G. G. Cytophysiology of the adrenal cortex. Int. Rev. Cytol., 98:1-405, 1986.

Pastorino, I. C.; Mugnaini, M. T.; Rolando, A. N.; RomaninI, M. C.; Rodriguez, M. I.; Soñez, C. A. \& Gauna, H. F. Effects of chronic stress on morphometrical variables of pregnant rats and their fetuses. Biocell, 22:71, 1998.

Porte, D. Jr. \& Robertson, R. P. Control of insulin secretion by catecholamines, stress, and the sympathetic nervous system. Fed. Proc., 32(7):1792-6, 1973.

Renshaw, D. \& Hinson, J. P. Neuropeptide Y and the adrenal gland: a review. Peptides, 22(3):429-38, 2001.

Romanini, M. C.; Rodríguez, N.; Mugnaini, M. T.; Rolando, A.; Soñez, C. A. \& Gauna, H. Effects of chronic stress by immobilization on the plasmatic levels of corticosterone in pregnant rats. Biocell, 23(1):89, 1999.

Rucinski, M.; Porzionato, A.; Ziolkowska, A.; Szyszka, M.; Macchi, V.; De Caro, R. \& Malendowicz, L. K. Expression of the spexin gene in the rat adrenal gland and evidences suggesting that spexin inhibits adrenocortical cell proliferation. Peptides, 31(4):676-82, 2010.

Silva, E. J.; Felicio, L. F.; Nasello, A. G.; Zaidan-Dagli, M. \& Anselmo-Franci, J. A. Prolactin induces adrenal hypertrophy. Braz. J. Med. Biol. Res., 37(2):193-9, 2004.

Soñez, C. A.; MugnainI, M.; Becú, D.; Rolando, A.; Romanini, M. C.; Díaz, M. C.; Rodríguez, M. I. \& Gauna, H. Effects of chronic stress on the plasmatic levels of PRL, FSH, LH, estradiol and progesterone in pregnant rats. Biocell, 14:81, 1996.
Soñez, C. A. Efectos del estrés crónico sobre algunas poblaciones celulares adenohipofisiarias durante la segunda mitad de la gestación en ratas. Tesis doctoral. Facultad de Ciencias Médicas. Universidad Nacional de Córdoba, 2001.

Swann, H. The pituitary-adrenocortical relationship. Physiol. Rev., 20:493, 1940.

Ulrich-Lai, Y. M.; Figueiredo, H. F.; Ostrander, M. M.; Choi, D. C.; Engeland, W. C. \& Herman, J. P. Chronic stress induces adrenal hyperplasia and hypertrophy in a subregion-specific manner. Am. J. Physiol. Endocrinol. Metab., 291(5):E965-73, 2006.

Viard, I.; Penhoat, A.; Ouali, R.; Langlois, D.; Bégeot, M. \& Saez, J. M. Peptide hormone and growth factor regulation of nuclear proto-oncogenes and specific functions in adrenal cells. J. Steroid. Biochem. Mol. Biol., 50(5-6):219-24, 1994.

Vinson, G. P. \& Ho, M. M. Origins of zonation: the adrenocortical model of tissue development and differentiation. Clin. Exp. Pharmacol. Physiol. Suppl., 25:S91-6, 1998.

Vinson, G. P. Adrenocortical zonation and ACTH. Microsc. Res. Tech., 61(3):227-39, 2003.

Wolkersdörfer, G. W. \& Bornstein, S. R. Tissue remodelling in the adrenal gland. Biochem. Pharmacol., 56(2):163-71, 1998.

\section{Correspondence to: \\ Biología Celular y Embriología \\ Dpto. de Anatomía Animal \\ Facultad de Agronomía y Veterinaria \\ Universidad Nacional de Río Cuarto \\ Ruta 8 Km 601 Campus Universitario ARGENTINA}

Email: abozzo@unrc.edu.ar

Received: 06-05-2011

Accepted: 04-07-2011 